\title{
LA CUESTIÓN MIGRATORIA CUBANA. ALGUNAS CONSIDERACIONES
}

THE CUBAN MIGRATION ISSUE. SOME CONSIDERATIONS

\author{
María Elena Cobas Cobiella \\ Universidad de Valencia, Valencia. España/Spain \\ $\underline{\text { m.elena.cobas@uv }}$
}

Recibido/Received: 03/05/2017

Modificado/Modified: 29/06/2017

Aceptado/Accepted: 10/10/2017

\section{RESUMEN}

El trabajo tiene como objetivo introducir algunas cuestiones de interés en relación a la normativa migratoria cubana, resaltando algunos conceptos de relevancia para la materia y sobre todo en el complejo mundo del derecho cubano sumergido en las indefiniciones. Destacando además la incidencia de esta norma en el ámbito de la persona y la autonomía de la voluntad.

\section{PALABRAS CLAVE}

Migración; nacionalidad; repatriación; habilitación; pasaporte; propiedad; herencia.

\section{SUMARIO}

1. Introducción. 2. Algunas notas preliminares sobre el tema migratorio cubano. 2.1. Referencia a la legislación en la materia. 2.2. Cuestiones claves de la normativa. 3. La inmigración y su incidencia en el ámbito de la persona. 4. Concluyendo en dos líneas. Bibliografía.

\section{ABSTRACT}

The paper aims to introduce some issues of interest in relation to Cuban migration regulations, highlighting some concepts of relevance in the subject and especially in the complex world of Cuban law immersed in uncertainties. It aims also to emphasize the incidence of this norm in the field of the person and the autonomy of the will.

\section{KEYWORDS}

Migration; Nationality; Repatriation; Qualification; Passport; Property; Inheritance.

\section{CONTENTS}

1. Introduction. 2. Some preliminary notes on the Cuban migratory theme. 2.1. Reference to legislation in the matter. 2.2. Key issues of the regulation. 3. Immigration and its incidence in the scope of the person. 4. Concluding on two lines. References. 


\section{INTRODUCCIÓN}

Vivimos en un mundo globalizado, razón por la cual la inmigración y las cuestiones referentes a la misma despiertan interés. En este entorno se ha encontrado siempre la polémica del tema migratorio cubano por ser antiguo en el tiempo, permanente y con muchas consecuencias jurídicas para los cubanos, tanto para los que viven en la Isla como para aquellos que no residen en Cuba.

Los orígenes del movimiento migratorio, como muchos autores afirman, pueden encontrarse en los inicios de la historia humana. El hombre y la humanidad en general se caracterizan por su dinamismo y su antisedentarismo, que desde épocas primitivas o remotas delatan sus incesantes desplazamientos. La colonización y la esclavitud atrajeron a nuestras tierras a un gran número de inmigrantes que junto a los nativos fueron conformando la población de los países de esta área (De Urrutia, 1997: 50)

Como señala alguna doctrina:

... la historia de las relaciones entre Cuba y Estados Unidos, la confrontación entre ambos países, tiene una incidencia en la formulación y aplicación de la política migratoria de cada país. La de Estados Unidos ha incluido el proceso de estimulación de la emigración ilegal y legal, cuyo peso ha variado por etapas, intereses y condicionantes políticos (De Urrutia, 1997: 52).

Efectivamente la polémica histórica entre ambos países ha marcado la angustiosa, o no, historia de cada cubano migrante, extendiéndose a todos los cubanos, que se hayan ido del territorio nacional, con independencia del lugar donde haya decidido vivir, bien puede ser Europa, África o Asia, o cualquiera que haya sido la causa para hacerlo, económica, política o simplemente porque quiere conocer otro lugar y residir en otra parte del mundo y por tanto sujetando a todas las personas no sólo al avatar de las relaciones entre ambos países, sino a un férreo sistema migratorio cubano que ha generado una distinción entre cubanos por su status migratorio.

La actualidad en sede de emigración está acotada por lo que se conoce como "la crisis migratoria cubana", que ya no se limita a la emigración a EE.UU., sino a otros países de Centroamérica y Sudamérica, que constituye una consecuencia de las conversaciones y el relanzamiento de las relaciones diplomáticas entre Cuba y EE.UU., el debate en torno a la Ley de Ajuste Cubano, la finalización de la política de pies secos y pies mojados, que ha dado un vuelco al destino de los cubanos y a su situación ventajosa, por llamarlo de alguna manera, en relación a los otros emigrantes que arribaban a las costas norteamericanas.

En fecha 12 de enero de 2017, el presidente de Estados Unidos Barack Obama derogó lo que se conoce como la "política de pies secos, pies mojados", poniendo fin al tratamiento especial que recibían los inmigrantes cubanos en relación a los otros inmigrantes. El gobierno de Cuba por su parte, accedió finalmente a recibir a los cubanos que fueron deportados de Estados Unidos, a quienes durante décadas no aceptó.

La temática de la inmigración constituye un problema político, económico, social y sobre todo profundamente personal porque afecta al ámbito de la persona física o natural y sus derechos fundamentales, entre los que destacan la libre circulación, la libertad, el derecho a la propiedad, a la libertad de empresa y a la herencia, e incluso a la familia, y sobre todo el tratamiento de la nacionalidad, la ciudadanía; cuestiones refrendadas en las distintas Constituciones y de manera peculiar en la Constitución Cubana de 1976, que curiosamente en una de las últimas modificaciones realizadas señala que la misma fue modificada con el fin de garantizar y ampliar el ejercicio de numerosos derechos y libertades fundamentales y 
los derechos civiles y políticos de los ciudadanos y extranjeros. Pero que constituye letra muerta para una gran parte de cubanos (Constitución de la República de Cuba, Gaceta Oficial de la República, Edición Extraordinaria, No 3, de 31 de enero de 2003).

En cualquier caso la cuestión es complicada, polémica y de quizás una sencilla solución, pero que al depender del status quo y del sistema político cubano no parece que en breve tendrá un acercamiento al tratamiento y regulación que en los países democráticos existe del tema, si se es nacional de un lugar, se es con todas las consecuencias que ello conlleva.

\section{ALGUNAS NOTAS PRELIMINARES SOBRE EL TEMA MIGRATORIO CUBANO}

La nacionalidad y la ciudadanía revisten una gran significación para el Derecho cuestión que no debe pasar inadvertida, a efectos de cualquier trabajo que se ocupe de ella, porque constituye a la par de un derecho fundamental un estado civil, que incide directamente en la capacidad de obrar de las personas, les acompaña desde su nacimiento y afecta sus leyes más personales, ya que constituye la ley nacional que regula la capacidad de sus ciudadanos en cualquier parte del mundo donde se encuentren y en su propio país, a lo que se une la connotación política por su carácter constitucional, aunque sea el Código Civil el que le regule jurídicamente (Cobas, 2013: 2).

En este punto cabe señalar que la Constitución cubana emplea el concepto de ciudadanía cubana, en vez de a nacionalidad cubana.

La Constitución Cubana (reformas del año 2003) regula en su art. 29 que son cubanos por nacimiento: a) los nacidos en el territorio nacional, con excepción de los hijos de los extranjeros que se encuentren al servicio de su gobierno o de organismos internacionales. La ley establece los requisitos y las formalidades para el caso de los hijos de los extranjeros residentes no permanentes en el país; b) los nacidos en el extranjero de padre o madre cubanos, que se hallen cumpliendo misión oficial; c) los nacidos en el extranjero de padre o madre cubanos, previo el cumplimiento de las formalidades que la ley señala; ch) los nacidos fuera del territorio nacional, de padre o madre naturales de la República de Cuba que hayan perdido la ciudadanía cubana, siempre que la reclamen en la forma que señala la ley; d) los extranjeros que por méritos excepcionales alcanzados en las luchas por la liberación de Cuba fueron considerados ciudadanos cubanos por nacimiento.

Posteriormente en el art. 30 establece que son ciudadanos cubanos por naturalización: a) los extranjeros que adquieren la ciudadanía de acuerdo con lo establecido en la ley; b) los que hubiesen servido a la lucha armada contra la tiranía derrocada el primero de enero de 1959, siempre que acrediten esa condición en la forma legalmente establecida; c) los que habiendo sido privados arbitrariamente de su ciudadanía de origen obtengan la cubana por acuerdo expreso del Consejo de Estado.

Siguiendo con el texto constitucional, los artículos 31, 32 y 33 también regulan la cuestión de la ciudadanía cubana, estableciendo el primero de ellos que "ni el matrimonio ni su disolución afectan la ciudadanía de los cónyuges o de sus hijos" (art. 31); el art. 32 por su parte resulta bastante interesante porque trata un tema bastante complejo, que es la pérdida de la ciudadanía cubana, así como la prohibición de que los cubanos ostenten la doble ciudadanía, regulando que:

... los cubanos no podrán ser privados de su ciudadanía, salvo por las causas legalmente establecidas. Tampoco podrán ser privados del derecho a cambiar de ésta. No se admitirá la doble ciudadanía. En consecuencia, cuando se adquiera una ciudadanía extranjera, se 
perderá la cubana. La ley establece el procedimiento a seguir para la formalización de la pérdida de la ciudadanía y las autoridades facultadas para decidirlo.

Finalmente el art. 33 establece que la ciudadanía cubana podrá recobrarse en los casos y en la forma que prescribe la ley.

Estos artículos son de corte general, contradictorios con leyes especiales, y no refrendan los derechos esenciales, de cualquier nacional de un país, como residir, votar, desempeñar funciones, cargos públicos entre otros. Tienen esa nota de programa o programática que caracteriza la Constitución cubana y dejan diversas cuestiones sin abordar o habiéndolas abordado sin resolver, creando vacíos legales.

\subsection{Referencia a la legislación en la materia}

La legislación en la materia de inmigración cubana ha estado marcada durante muchos años por cierto oscurantismo, quizás por la falta de publicidad de las normas cubanas y de difícil conocimiento para los que quieren acceder a ella. Tampoco es que haya sido demasiado profusa, manteniéndose inalterable durante casi cincuenta años, estática, ajena a la realidad exterior y extremadamente peculiar.

Algunos antecedentes legislativos en el tema los podemos encontrar en la Resolución No 454 de 29 de septiembre de 1961 del Ministerio del Interior (Resolución No. 454 d e 29 de septiembre de 1961 del Ministro del Interior. Gaceta Oficial de la República No. 196 del 9 de octubre de 1961, página 19310.), que estableció que las personas que abandonaban el territorio nacional, lo hacían en relación a sus propiedades, y que no eran afines a los principios de la Revolución, expresando en sus motivos:

Por cuanto: El Gobierno Revolucionario ha venido constatando que personas que salen del territorio nacional, abandonan sus propiedades, tales como bienes muebles e inmuebles, dejándolos en poder de familiares, amigos o testaferros, con el deliberado propósito de burlar las disposiciones de la Revolución. Por cuanto: No es permisible que continúen sucediendo estos hechos, constitutivos de delitos, llevados a cabo por elementos contrarios a los principios y orientaciones populares de la Revolución Socialista.

Seguidamente regulaba que:

... los ciudadanos que salen del territorio nacional con rumbo a Estados Unidos de Norte América, se les concederá un permiso hasta de veinte y nueve días; de sesenta días para los viajeros que se dirigen al resto de los países del Continente americano, y de noventa días a los que embarquen hacia el Continente Europeo. Vencidos los términos señalados, si no regresan, se considerará que abandonan definitivamente el territorio nacional y en su consecuencia el Estado procederá a adjudicar los bienes muebles, inmuebles y demás valores pertenecientes a dichas personas.

Diversas incongruencias y ausencia de un respaldo jurídico serio, así como algunas omisiones, hicieron que el 5 de diciembre de 1961, el Consejo de Ministros, promulgara la Ley No. 989, que dispuso la nacionalización mediante confiscación a favor del Estado cubano de los bienes, derechos y acciones de los que se ausenten definitivamente del territorio nacional, que mantuvo vigente la confiscación de los bienes de los cubanos hasta la promulgación del Decreto- Ley No 302 publicado en la Gaceta Oficial de Cuba No 44,en fecha 16 de octubre, que modificó la Ley No 1312, Ley de Migración de 20 de septiembre de 1976, que deroga en su Disposición Final Cuarta la citada ley, con el argumento de la necesidad de establecer nuevos conceptos, que se atemperen al escenario actual. 
El no savoir faire del legislador cubano condujo a que a efectos prácticos con las sustanciales y afortunadas reformas del año 2011 en materia de propiedad, la citada ley fuera minimizada o no aplicada, porque ya desde ese año, en consonancia con Los Lineamientos del Partido Comunista de Cuba, se aprobaron normas que permitieron la venta de inmuebles y coches por parte de sus titulares antes de abandonar el país, aunque sin derogarla, como hubiera correspondido.

Así resulta de lo previsto en el Decreto- Ley No 288, modificativo de la Ley No 65, Ley General de la Vivienda, que establece en su art. 81.1 que la vivienda de residencia permanente, cuyo titular haya salido definitivamente del país, es confiscada por el Estado al efecto de poder transmitir su propiedad a las personas que tienen derecho a ello, con arreglo a lo dispuesto en la presente Ley (Gaceta Oficial Extraordinaria, No 35, de 2 de noviembre de 2011). En igual sentido el art. 8.8 regula que: son válidos los actos de transmisión de la propiedad de viviendas, realizados por sus propietarios, conforme a la Ley, antes de salir definitivamente del país.

Cabe además hacer referencia en este epígrafe a la Ley de Migración de 1976 y al Reglamento correspondiente de 1978, que trazaron la política y el devenir migratorio cubano durante más de 30 años.

Lo más destacado de la Ley $\mathrm{N}^{\circ} 1312$ de 20 de septiembre de 1976, Ley de Migración, es la regulación en el art. 1 donde establece el "famoso permiso" de entrada o salida a territorio nacional, al establecer en su art. 1 que :

... los ciudadanos cubanos, para salir del territorio nacional o entrar al mismo, deberán poseer expedido a su nombre, alguno de los siguientes documentos: a) Pasaporte Diplomático, b) Pasaporte de Servicio, c) Pasaporte Oficial, ch) Pasaporte Corriente, d) Pasaporte de Marino". Estableciendo además en el segundo párrafo que: "los que poseyeran pasaporte Corriente, deberán además obtener el correspondiente permiso de entrada o de salida, otorgado por el Ministerio del Interior.

A ello hay que añadir una serie de trámites, algunos de los cuales se han ido quedando por el arduo camino de entrar o salir de Cuba, como fue la carta de invitación, que se exigía antes de las reformas migratorias a los ciudadanos cubanos residentes en Cuba que viajaban por asuntos particulares al extranjero, que debían de presentar una carta bien realizada por un ciudadano extranjero o por un cubano residente en el exterior, quien debía de comprometerse económica y legalmente con la persona que invitaba ante las autoridades correspondientes del país donde residía quien invitaba al ciudadano cubano. Que ya en su momento no sólo era un absurdo, sino objeto de críticas por los organismos internacionales.

La carta de invitación fue dejada sin efecto por la Resolución No 318 de Relaciones Exteriores, en fecha 13 de octubre de 2012, con entrada en vigor en 14 de enero de 2013 (Resuelvo Primero).

La citada carta de invitación explica algún sector de la doctrina, que en 2013, el Estado tácitamente declaraba la incapacidad económica de los cubanos para viajar y ello conllevó la eliminación del permiso de salida conjuntamente con el trámite migratorio de la carta (Diversent, 2014).

El Decreto No 26, Reglamento de la Ley de Migración de 19 de julio de 1978 por su parte reguló en su momento todo el desarrollo de la tramitación migratoria como los pasaportes, la clasificación de los mismos, así como otras cuestiones de interés, que serán tratadas con posterioridad.

La Ley No 1312, Ley de Migración fue modificada por el Decreto- Ley No 302, de 11 de octubre de 2012, Gaceta Oficial, Edición Ordinaria número 44 en fecha 16 de octubre de 
2012, mientras que el Decreto No 26, Reglamento de la Ley de Migración de 19 de julio de 1978, fue modificado por el Decreto No 305, de 11 de octubre de 2012, publicado en Gaceta Oficial Gaceta Oficial, Edición Ordinaria No 44 en fecha 16 de octubre de 2012, ambos con entrada en vigor en fecha 14 de enero de 2013.

El Decreto No 306, de 11 de octubre de 2012, Gaceta Oficial, Edición Ordinaria No 44 en fecha 16 de octubre de 2012, regula por su parte, el tratamiento hacia cuadros, profesionales y atletas que requieren autorización para viajar al exterior.

Recientemente el Decreto Ley No. 327, de 31 de enero de 2015, por su parte modificó la Ley No. 1312 "Ley de Migración", mientras que el Decreto 26 fue actualizado en fecha 18 de diciembre de 2015, Gaceta Oficial no 41, Extraordinaria, y concordado con el Decreto no. 305 de 11 de octubre de 2012 (publicado en Gaceta Oficial Ordinaria no. 44 de 16 de octubre de 2012) y el Decreto no. 330 de 29 de julio de 2015 (Gaceta Oficial Extraordinaria no. 29 de 27 de agosto de 2015).

El art. 1, modifica los art. 1, 3, 4 y 13, estableciendo que el pasaporte es un certificado de identidad y ciudadanía que se expide para surtir efectos solo en cuanto a la admisión y estancia de su titular en el extranjero como ciudadano cubano y, que no obstante, se admitirá como documento de identidad válido en el territorio nacional, el pasaporte de ciudadanos cubanos que residen permanentemente en el extranjero, cuando su titular se encuentre en Cuba. Sus modificaciones resumidamente se refieren a tramitación de los pasaportes, pero se mantienen las categorías esenciales y procedimiento en materia migratoria. Incidiré en ello en epígrafes posteriores.

\subsection{Cuestiones claves de la normativa}

El Decreto-Ley No 302, de 16 de octubre de 2012 regula algunas cuestiones claves en sede de migración cubana, así caben destacar entre sus conceptos más relevantes y de importancia, el de ciudadano cubano emigrado que es aquél, que viaja al exterior por asuntos particulares y permanece de forma ininterrumpida sin la autorización correspondiente, así como cuando se domicilia en el exterior sin cumplir las regulaciones migratorias vigentes (Art. 9.2).

La obtención del pasaporte cubano tampoco está al acceso de todos los cubanos, a tenor de lo que regula el art. 23 de la Ley, que establece una serie de personas o situaciones que excluyen el derecho a obtener el pasaporte, entre las que destacan las siguientes:

a) Estar sujeto a proceso penal, siempre que haya sido dispuesto por las autoridades correspondientes. b) Tener pendiente el cumplimiento de una sanción penal o medida de seguridad, excepto en los casos que se autorice de forma expresa por el tribunal. c) Encontrarse sujeto al cumplimiento de las disposiciones sobre la prestación del Servicio Militar. d) Cuando razones de Defensa y Seguridad Nacional así lo aconsejen. e) Tener obligaciones con el Estado cubano o responsabilidad civil, siempre que hayan sido dispuestas expresamente por las autoridades correspondientes ff) Carecer de la autorización establecida, en virtud de las normas dirigidas a preservar la fuerza de trabajo calificada para el desarrollo económico, social y científico-técnico del país, así como para la seguridad y protección de la información oficial. g) Los menores de edad o incapaces, que no cuenten con la autorización de los padres o representantes legales, formalizada ante Notario Público. h) Cuando por otras razones de interés público lo determinen las autoridades facultadas. i) Incumpla los requisitos exigidos en la Ley de Migración, su Reglamento y en las disposiciones complementarias relacionadas con la solicitud, emisión y otorgamiento de pasaportes. 
De la lectura de este precepto podemos decir que son bastantes las prohibiciones para obtener un pasaporte cubano, llamando la atención a la limitante establecida en el art. 23. f) que veta directamente a las personas con estudios universitarios, fuerza de trabajo calificada a solicitar una autorización para salir del país, seguido del inciso h) que deja abierta la negativa a obtener el documento a las razones de interés público, que conociendo bien Cuba, puede ser cualquier causa, y que por demás no aparecen desarrollas o siquiera delimitadas, dejando a un incierto destino desdichado la obtención del mismo, y vetando a quien ha estudiado y trabajado para poder obtener el citado documento oficial.

$\mathrm{El}$ art. 24.1 de la ley establece las causales que impide la entrada en el territorio nacional, mientras que el art. 25 establece las causales que impiden la salida del territorio nacional. Estas causales además de ser aleatorias, no cuentan con un procedimiento establecido con garantías y seguridad jurídica suficiente ni en vía administrativa ni por vía judicial, por lo menos a efectos de la norma.

Entre las causales que marca la ley para la entrada al país tenemos las siguientes, bajo el término de inadmisibles y en el argot cubano "retornados".

a) Tener antecedentes de actividades terroristas, tráfico de personas, narcotráfico, lavado de dinero, tráfico de armas u otras perseguibles internacionalmente. b) Estar vinculado con hechos contra la humanidad, la dignidad humana, la salud colectiva o perseguibles en virtud de tratados internacionales de los que Cuba es parte. c) Organizar, estimular, realizar o participar en acciones hostiles contra los fundamentos políticos, económicos y sociales del Estado cubano. d) Cuando razones de Defensa y Seguridad Nacional así lo aconsejen. e) Tener prohibida su entrada al país, por estar declarado indeseable o expulsado. f) Incumplir las regulaciones de la Ley de Migración, su Reglamento y las disposiciones complementarias para la entrada al país.

En el apartado 2 se establece que la autoridad migratoria puede poner a disposición de las autoridades competentes, a las personas comprendidas en el Apartado 1 de este art., cuando el hecho es perseguible en el territorio nacional conforme a la Ley y los tratados internacionales de los que Cuba es parte. Permitiendo que cuando razones humanitarias o de interés estatal así lo aconsejen se podrá autorizar la entrada de los cubanos.

El art. 25 entre las causas que impiden la salida del país refiere los siguientes supuestos:

a) Estar sujeto a proceso penal, siempre que haya sido dispuesto por las autoridades correspondientes. b) Tener pendiente el cumplimiento de una sanción penal o medida de seguridad, excepto en los casos que se autorice de forma expresa por el tribunal. c) Encontrarse sujeto al cumplimiento de las disposiciones sobre la prestación del Servicio Militar. d) Cuando razones de Defensa y Seguridad Nacional así lo aconsejen. e) Tengan obligaciones con el Estado cubano o responsabilidad civil, siempre que hayan sido dispuestas expresamente por las autoridades correspondientes. f) Carecer de la autorización establecida, en virtud de las normas dirigidas a preservar la fuerza de trabajo calificada para el desarrollo económico, social y científico-técnico del país, así como para la seguridad y protección de la información oficial. g) Los menores de edad o incapaces, a quienes les sea revocada la autorización de los padres o representantes legales, formalizada ante Notario Público. h) Cuando por otras razones de interés público lo determinen las autoridades facultadas. I) Incumpla los requisitos exigidos en la Ley de Migración, su Reglamento y en las disposiciones complementarias para salir del país.

El Decreto No 305, modificativo del Reglamento de la Ley de Migración de 19 de julio de 1978 entre las cuestiones más destacadas aparecen, algunas no tan novedosas como resulta la 
de concesión al Ministerio del Interior de la confección de los pasaportes y de los certificados de identidad y de viaje (Art. 4 de la citada norma).

El art. 44 regula el requisito de la habilitación, que es el permiso o autorización que tienen que solicitar los emigrados cubanos para poder entrar en Cuba, sin el cual no es posible entrar en Cuba. La norma no define en qué consiste la habilitación, ni los presupuestos y el procedimiento para obtenerla, ni las causas que la pueden denegar, ni el proceso a seguir en caso de denegación de ésta. En relación a este vacío legal opina con acierto la doctrina en la materia:

... estas omisiones, le permite al Estado negar la entrada a un nacional al país, sin tener que reconocer si su decisión denegatoria, está fundada en motivaciones políticas (Diversent, 2014).

El art. 46 de la normativa es bastante curioso y de improbable cumplimiento, porque establece el supuesto de quien habiendo poseído la ciudadanía cubana, solicite la entrada en el territorio nacional como titular de pasaporte extranjero, deberá presentar al solicitar la visa y en el momento en que le sea practicado el despacho migratorio de entrada, la prueba documental de que se ha dispuesto por autoridad competente la pérdida de su ciudadanía cubana, sin este requisito no le será expedida su visa, ni admitido como extranjero en Cuba.

La Constitución cubana como ya he referido permite la renuncia a la ciudadanía, pero no existe procedimiento legal para hacerlo, porque la ley no lo establece.

El art. 47.1 establece dos plazos, un primer plazo de permanencia en el territorio nacional para los cubanos emigrados: los ciudadanos cubanos emigrados pueden permanecer hasta 90 días en sus visitas a Cuba, un segundo plazo más extenso de 180 días para los ciudadanos con residencia en el exterior. La regulación que hace este artículo es diferenciadora entre cubanos de acuerdo a la situación migratoria de cada uno.

El Decreto No 306 , de 11 de octubre de 2012, que regula por su parte, el tratamiento hacia cuadros, profesionales y atletas que requieren autorización para viajar al exterior, establece en el art. 3 la necesidad de la autorización de las personas comprendidas en el art. 1, para poder viajar al exterior por asuntos particulares, que será concedida por los jefes de los órganos, organismos, entidades nacionales, consejos de administración y organizaciones superiores de dirección empresarial autorizada, denominados jefes facultados.

Los sujetos destinatarios de esta norma, comprendidos en el art. 1 son los siguientes: cuadros categorizados como directivos superiores y directivos en los aparatos centrales de los órganos, organismos, entidades nacionales, consejos de la Administración y organizaciones superiores de dirección empresarial, así como los directivos y ejecutivos que se desempeñan en actividades vitales para el desarrollo económico, social y científico-técnico del país y en cargos con facultades decisorias sobre los recursos financieros y materiales; graduados de la educación superior que realizan actividades vitales para el desarrollo económico, social y científico-técnico del país en los programas estratégicos, proyectos de investigación y servicios de salud; (Se aplica a partir del 7 de diciembre 2015 para las salidas al exterior por asuntos particulares de profesionales médicos de diferentes especialidades que realizan actividades vitales en los servicios de salud a la población y en la actividad científicotécnica); técnicos de nivel medio especializados que realizan actividades vitales para mantener los servicios de salud y la actividad científico-técnica; atletas de alto rendimiento, técnicos y entrenadores vitales para el movimiento deportivo cubano".

$\mathrm{El}$ art. 2, por su parte, establece el procedimiento, tratamiento y plazos para los sujetos que se hallen en estos supuestos y quieran viajar al extranjero, regulando que: 
a) Los comprendidos en los incisos a), b) y d) pueden ser autorizados, previo análisis de cada caso, a viajar al exterior por asuntos particulares. Cuando la solicitud es para residir en el exterior, son autorizados en un plazo que no exceda de cinco años naturales, desde la fecha en que se solicita. Durante este plazo se realiza el entrenamiento del relevo en la actividad vital de que se trate, en los casos que corresponda.

b) Los comprendidos en el inciso c) reciben similar tratamiento a lo establecido en el numeral anterior. Cuando la solicitud es para residir en el exterior, se autorizan en un plazo que no exceda de los tres años naturales, desde la fecha en que se solicita.

Para los sujetos comprendidos en el Art. 1, la desvinculación del trabajo no exonera del cumplimiento de los plazos establecidos para que se autorice la solicitud de residir en el exterior.

Cuando el jefe facultado considere que existen razones humanitarias, autoriza la salida al exterior de los sujetos de este Decreto, incluidos en las regulaciones anteriores, sin atenerse a los términos establecidos. En el caso de los cuadros se cumple el procedimiento específico dictado a esos efectos, de forma expedita.

En relación a estas modificaciones que se han realizado en materia migratoria en Cuba, si bien han agilizado los innumerables trámites para poder salir, viajar o entrar al territorio nacional, siguen manteniendo la línea dura y el absurdo jurídico que impide que los cubanos entren y salgan libremente de su lugar de nacimiento. Profundizando las diferencias entre los cubanos, que se generan por la vía que se ha utilizado para salir del territorio nacional, y empleando el concepto de abandono del territorio nacional, que ya de por sí hace aparecer un sentimiento de culpa, de destierro y la idea que, quien se va, traiciona; y convirtiendo a quien lo hace en una persona vetada para entrar, desterrada y sin amor a la Patria, estableciendo, por si fuera poco, un oscuro camino para poder volver a vivir en Cuba, la llamada repatriación.

Este instrumento ha existido históricamente en Cuba, pero era de uso casi restrictivo y con determinados requerimientos, lo cual es lógico porque como toda categoría jurídica se hace con una finalidad, que las personas puedan regresar a su casa, a su país para vivir, por enfermedad, o por encontrarse en determinados supuestos humanitarios, no con el fin que se está empleando actualmente, como expresión más del folklore cubano, que no ha dejado en estas últimas décadas de estar presente en la realidad cubana y que el derecho a la larga ha tenido que incorporar en la construcción de nuevas categorías jurídicas.

El art. 48.1 del Reglamento de la Ley Migratoria establece su regulación:

... los ciudadanos cubanos emigrados que pretender establecer su residencia en el territorio nacional lo solicitan ante las representaciones diplomáticas o consulares, o ante la oficina de trámite del Ministerio del Interior que corresponda, cuando se encuentren en Cuba.

El apartado 2 establece los procedimientos para la tramitación de las solicitudes a que se refiere el apartado anterior.

La Resolución No 44, de 13 de octubre de 2012, que entró en vigor el 14 de enero de 2013, resuelve el procedimiento para resolver las solicitudes de residencia en el territorio nacional que presentan los ciudadanos cubanos emigrados. Los requisitos exigidos por la norma es la presentación de la solicitud, presentación del pasaporte corriente vigente, informar la persona de referencia que en Cuba se compromete a garantizar su alojamiento y manutención cuando corresponda, hasta tanto el interesado pueda disponer de vivienda e ingresos propios, pagar impuesto o arancel consular correspondiente, debiendo además la 
persona informar sobre la vía utilizada para emigrar y las causas para solicitar la residencia nuevamente en Cuba, los datos de identidad y de los menores de edad o incapaces que lo acompañen.

La Dirección de Inmigración y Extranjería es la responsable en el plazo de 90 días para resolver sobre la solicitud y se notifican a través de los Consulados o las Oficinas de Trámites del Ministerio del Interior (art. 4).

En la actualidad cubana es la vía que tienen los cubanos residentes en el exterior y que habían perdido sus derechos legales en Cuba a obtener de nuevo su residencia legal en la isla $\mathrm{y}$, por ende, recuperar sus derechos como ciudadano cubano. Hoy es un derecho por el que todos los cubanos pueden optar. (Cantón, 2016).

La repatriación tampoco está abierta a todos los cubanos, de ahí que como todas las cuestiones en este tema están sujetas a la decisión de terceras personas, específicamente en el órgano de control cubano sobre la vida y destino de los cubanos, el Ministerio del Interior; habida cuenta que aunque se pueda presentar en los Consulados cubanos en el exterior, estos constituyen una extensión del Ministerio del Interior cubano y su personal es designado como tal. Y por supuesto sería ingenuo pensar que la puedan obtener todos los cubanos, a pesar de que es la tónica que se ofrece a los cubanos.

Este instrumento legal está empleado por muchos cubanos para poder acceder a Cuba, como ya se ha dicho, y optar por los mismos derechos de los que viven allí, pero sin perder los derechos que tienen en los países que en su momento los acogieron, o en los países donde tienen su residencia habitual o la ciudadanía y como siempre poder hacer uso de un derecho que tienen desde su nacimiento en tierra cubana, vivir en el territorio cubano y entrar y salir sin limitaciones.

En el año 2015 se han producido modificaciones o actualizaciones en la normativa migratoria cubana, publicadas en la Gaceta Oficial Extraordinaria No. 41, de 18 de diciembre de 2015, que en general mantienen la misma tónica de la ley de 2012, con algunas variaciones en relación a la nomenclatura de los organismos, o la del art. 1 del Reglamento que queda modificado de la siguiente forma:

El pasaporte un certificado de identidad y ciudadanía que se expide para surtir efectos solo en cuanto a la admisión y estancia de su titular en el extranjero como ciudadano cubano. No obstante, se admitirá como documento de identidad válido en el territorio nacional, el pasaporte de ciudadanos cubanos que residen permanentemente en el extranjero, cuando su titular se encuentre en Cuba. Eliminando de su redacción el requisito de los 90 días, como plazo de validez de estos pasaportes para circular en Cuba.

\section{LA INMIGRACIÓN Y SU INCIDENCIA EN EL ÁMBITO DE LA PERSONA}

La primera cuestión que interesa destacar es que la Ley migratoria cubana se sustenta en la distinción entre cubanos en dependencia de su status migratorio y su lugar de residencia, por lo tanto un cubano que reside en el extranjero habiendo abandonado el territorio nacional, bajo determinadas circunstancias, tasadas por la política migratoria cubana no ostenta los mismos derechos que un cubano que reside en el país y está vetado para el ejercicio de diversos derechos, todos fundamentales e inherentes a la persona.

Por lo tanto, una de las cuestiones más acuciantes en el tema Cuba, no lo es sólo las relaciones con otros países, siempre habrá algún Estado, con el cual las relaciones exteriores no sean favorables, el problema es interno, es la política cubana, el sistema que ha generado y que en el momento actual que se vive es inoperante y lo que es peor, frena el desarrollo del 
país en todos los sentidos. Un país es fuerte cuando puede contar con todos sus nacionales, residan donde residan.

Matizando la cuestión cabe señalar que han existido diversos status migratorios como el permiso de viaje al exterior, el permiso de residencia en el exterior (PRE), los emigrados y los repatriados entre otros. Las consecuencias jurídicas de los mismos son diversas y afectan directamente en los derechos de los cubanos en el ámbito constitucional, administrativo, mercantil y civil y como a las reses marca a los cubanos, y los diferencia.

Esta diferencia lo es no sólo en relación a los que residen en Cuba, sino también entre los que residen en el extranjero.

El tratamiento migratorio entra en primer lugar en contradicción con lo establecido por la Constitución cubana que es como cualquier otra, la ley de leyes, la Carta Magna que rige a un país, aunque de una lectura rápida de la misma no parece inferirse, que exista un tratamiento desigual entre cubanos.

Tomemos como ejemplo el art. 132 de la Constitución cubana que preceptúa: tienen derecho al voto los cubanos, hombres y mujeres, mayores de dieciséis años de edad, excepto los incapacitados mentales, los inhabilitados judicialmente por causa de delito. Entonces ¿cabría que pudiera votar en Cuba un cubano que no resida en el territorio nacional?

La respuesta es negativa, no es posible ello, aunque no se infiera de la lectura del texto constitucional.

La segunda cuestión a destacar es la facultad discrecional concedida al Ministerio del Interior, que es el organismo qué decide en definitiva quién entra o sale del territorio nacional (Diversent, 2014). Todo ello en correspondencia con la forma en que la persona haya salido del país y con la concesión por parte del Estado de una categoría u otra migratoria. Resumiendo unos pueden entrar o salir con mayor o menor dificultad, porque en definitiva todos los cubanos han de pasar por uno u otro proceso, no existe una libre circulación, es algo como Sísifo en la mitología griega que fue castigado a llevar una piedra hasta la cima de una montaña, y antes de llegar, la piedra volvía a rodar hacia abajo, infinitamente.

Las nuevas modificaciones en el tema, tampoco resuelven el problema de la doble ciudadanía, que prohíbe la Constitución. El gobierno no priva a sus nacionales del cambio de ciudadanía, pero tampoco les permite renunciar a la cubana. En la práctica ignora el hecho de que un cubano residente en el exterior ostente la ciudadanía de otro estado, por tanto no se reconoce a ninguno de sus ciudadanos otra ciudadanía que no sea la cubana.

En otras palabras, una persona puede tener varias nacionalidades, sin embargo, para los efectos legales dentro de Cuba sigue siendo ciudadano cubano y no hay fórmula o procedimiento para renunciar a la ciudadanía cubana, aun cuando se infringen disposiciones constitucionales. Legalmente aun la Asamblea Nacional no ha determinado que autoridad decreta la pérdida de la ciudadanía. Es uno de los factores que les asegura el control del flujo migratorio, nos dice Diversent (2014).

Esto por una parte. Al otro lado, se encuentra el derecho civil, que es uno de los ámbitos más afectados por la política migratoria, a pesar de que el art. 1 del Código Civil cubano establece que esta disciplina regula relaciones patrimoniales y otras que no lo son, entre personas situadas en plano de igualdad, al objeto de satisfacer necesidades materiales y espirituales, y que los cubanos siguen ostentando la ciudadanía cubana, al no existir el reconocimiento de la doble ciudadanía, como se ha referido con anterioridad, sin embargo a efectos de aplicación de este Código y de las leyes especiales en la materia, no lo son, y si lo son en algún que otro caso, es para perjudicarlos. La eterna contradicción de las leyes cubanas y de su aplicación. 
Las repercusiones en el ámbito del Derecho civil son importantes, así los llamados emigrados no ostentan los mismos derechos que los han obtenido un permiso de residencia en el exterior y aunque la tramitación en ambos casos pueda ser fatigosa y en algunos casos dramática y costosa, no les ha privado a estos últimos de los derechos adquiridos en Cuba, ni sus bienes les fueron confiscados, ni están incapacitados para suceder, porque aunque ahora en la actualidad está permitido que puedan vender sus viviendas, durante más de 50 años, ha estado prohibido en Cuba la compraventa de viviendas. De forma tal que la persona que decidía vivir fuera de Cuba, y no regresaba en el plazo fijado por el Estado cubano, 12 meses hasta hace bastante poco, en la actualidad 24 meses, se convertía en un desertor y automáticamente se producía la pérdida de derechos civiles; cuestión que se ha mantenido invariable, porque como preceptúa la ley, las actuales modificaciones no cambian el status de los que emigraron con anterioridad a las modificaciones. Una ley irretroactiva en lo que a beneficios se refiere.

No sería consecuente con la realidad, no decir que las palabras escoria, gusano, desertor se han ido matizando con el tiempo hasta convertirse en la palabra emigrado, que es mucho más suave para quien la escucha, pero que tiene la misma connotación o casi idéntica que tuvo en los primeros años de Revolución, sensación de destierro, de tener que pedir permiso para entrar o salir, y estar condenado a no volver por la decisión de un poder político omnipresente y que afecta a la condición de los nacionales cubanos.

Cabe aquí hacer una pequeña matización, aunque se emplea en el trabajo la categoría de emigrado, que es la que la legislación refiere, se utiliza también la categoría de exiliado en los foros y en diversos ámbitos, pero con otras connotaciones mucho más políticas, históricas y sociales que no constituyen el objetivo de este trabajo.

Ser un emigrado significaba, y significa, la pérdida del derecho real por excelencia, la propiedad de tus bienes tanto muebles como inmuebles, porque las modificaciones del 2011 no permiten que los emigrados mantengan su propiedad en Cuba, lo que se les concede es el derecho a venderlas.

¿Cuáles son las limitaciones que tiene un emigrado cubano en relación al ámbito patrimonial y personal?

En relación al art. 12 del Código Civil cubano que establece que la capacidad civil de las personas para ejercer sus derechos y realizar actos jurídicos se rige por la legislación del Estado del cual son ciudadanos, cabe destacar que como en sede de Derecho cubano no se reconoce la doble ciudadanía, y por tanto los cubanos siguen siendo ciudadanos cubanos todos; cabría entonces tanto la aplicación de este art. y lo preceptuado en el art. 24 de la Constitución cubana que regula el derecho de herencia sobre la vivienda de dominio propio y demás bienes de propiedad personal. Pero resulta que la realidad jurídica no es así.

De forma tal que los emigrados cubanos no pueden ejercer ninguno de estos derechos. Encontrándose si cabe hacer un paralelismo, como si se encontrarán en "muerte civil".

En primer orden de cosas no tienen el derecho a la herencia, no pudiendo suceder en Cuba, porque se sigue manteniendo el art. 470 del Código Civil cubano que regula:

“... es también causa de incapacidad para ser heredero o legatario el hecho de haber abandonado definitivamente el país" que como ya señalé hace mucho tiempo constituye una incapacidad política y no sucesoria. "La causa principal por la cual estas personas no pueden suceder es abandonar definitivamente nuestro país, por no estar de acuerdo con el sistema económico, político y social, de los que se deriva el matiz político que la misma lleva implícito" (Cobas, et al. 1992). 
En lo concerniente a la transmisión de la propiedad, en concreto a la transmisión de la vivienda, como parte del cumplimiento de los Lineamientos aprobados en el Sexto Congreso del Partido Comunista de Cuba en abril pasado, el Consejo de Estado publicó el Decreto-Ley No 288, de 28 de octubre de 2011 que modifica la "Ley General de la Vivienda", Ley No 65, de 23 de diciembre de 1988. (Gaceta Oficial de la República de Cuba, No 035, de 2 de noviembre de 2011).

La nueva normativa permite a los propietarios, cubanos y extranjeros residentes permanentes en el país, disponer libremente de sus viviendas, por medio de permutas, donaciones y compraventa; porque la disposición del Consejo de Estado eliminó la autorización de la Dirección Municipal de la Vivienda exigida a los propietarios que decidieran permutar o donar sus inmuebles, no obstante este logro, deja intactas las normas migratorias para la capital y para las zonas sometidas a régimen especial de administración, que impiden el pleno ejercicio del derecho de propiedad. El derecho a una vivienda a tenor del art. 2, es sólo a favor de quien resida en el país, y a los extranjeros residentes permanentes en el territorio nacional, de ahí que los emigrados cubanos tampoco pueden comprar en Cuba (Cobas, 2015).

El Decreto No. 292, Gaceta Oficial Extraordinaria de la República de Cuba, de 27 de septiembre de 2011, que fue derogado, por el Decreto Ley No. 320 de 31 de diciembre de 2013, regula otro de los grandes cambios en materia de propiedad y de bienes, la posibilidad de traspaso de los vehículos. En el mismo se establecen los principios y procedimientos para la tramitación y transmisión de la propiedad de los vehículos de motor, y se regula la transmisión de los coches por compraventa y donación, flexibilizándose esta, y permitiendo la compraventa o donación entre personas naturales cubanas residentes en Cuba y extranjeras con residencia permanente, temporal o de inmobiliaria (art. 2).

La posibilidad de invertir en Cuba, tampoco es favorable a los cubanos en general, porque la Ley de Inversión Extranjera, No. 118/2014, (Ley de la Inversión Extranjera", aprobada en fecha 29 de marzo de 2014, y publicada en abril de 2014, que derogó la Ley No 77, "Ley de la Inversión Extranjera", de 5 de septiembre de 1995, que a su vez remplazó el Decreto- Ley No 50., "Sobre asociación económica entre entidades cubanas y extranjeras", del 15 de febrero de 1982) excluye la posibilidad de los cubanos residentes en Cuba, de poder invertir y realizar sus negocios, incluso en asociación con personas residentes en el exterior, el inversionista nacional, siempre será una persona jurídica de nacionalidad cubana, con domicilio en el territorio nacional, que participa como accionista en una empresa mixta, o sea parte en un contrato de asociación económica internacional de acuerdo a lo previsto en el art. 2.m) (Cobas, 2014: 436). Regulación, perjudicial a los cubanos en general, y sobre todo a los que residen en Cuba.

El trabajo por cuenta propia también se encuentra limitado por las normas migratorias, así los sujetos que pueden ser trabajadores por cuenta propias son los ciudadanos cubanos y extranjeros residentes permanentemente en Cuba, mayores de 17 años de edad-que es la edad laboral en Cuba- siempre que cumplan los requisitos establecidos en la ley. (Cobas, 2016: p. 50). Lo que excluye expresamente a los cubanos que viven fuera del país, a asociarse con los cubanos que residen en Cuba, para fomentar y desarrollar la pequeña y mediana empresa, o la futura empresa familiar cubana.

Los derechos a solicitar créditos (Gaceta Oficial Extraordinaria, No 040, 21 noviembre de 2011, Decreto- Ley No 289), a inscribir los derechos de propiedad (Gaceta Oficial de la República de Cuba, Edición Extraordinaria No 39, de 16 de agosto de 2007), etc., o todo lo concerniente al marco contractual, registral y obligacional no es de aplicación a los cubanos emigrados, porque al faltar el requisito de la residencia, automáticamente se excluyen todas 
las relaciones jurídicas y la norma, en algunos casos, lo excluye expresamente y en otros casos no los incluye como sujetos destinatarios de las mismas. Haciendo prevalecer a los extranjeros con residencia permanente sobre los propios cubanos.

\section{CONCLUYENDO EN DOS LÍNEAS}

El tema cubano es complejo, y lacerante para quien lo ha tenido y tiene que sufrir.

En concreto el tema migratorio que nos ocupa, está plagado de oscurantismo y de una legislación que ha sido hasta hace muy poco desconocida, por razones propiamente políticas, más que jurídicas, económicas y sociales. La cuestión migratoria cubana está totalmente apartada tanto del sentido común que debe regir la actuación del derecho, de la política legislativa y del panorama internacional, rayando en ocasiones en lo absurdo.

Razones pueden ser varias. Pero insistir en ello sería no ofrecer margen a la imaginación de lector. Recordemos que son sólo consideraciones.

Las reformas migratorias aunque han ampliado plazos y han sistematizado de alguna forma el tema, siguen reflejando la distinción entre los cubanos a los efectos de sus derechos civiles y derechos en general, en dependencia de su status migratorio y su lugar de residencia, por lo tanto un cubano que reside en el extranjero habiendo abandonado el territorio nacional, bajo determinadas circunstancias, tasadas por la política migratoria cubana no ostenta los mismos derechos que un cubano que reside en el país y está vetado para el ejercicio de diversos derechos, todos fundamentales e inherentes a la persona.

La legislación civil se encuentra profundamente afectada por las leyes migratorias cubanas, esto es evidente y constituye una cuestión que no es posible desdeñar, si queremos en un futuro la construcción de una sociedad cubana mejor.

Espero que estas líneas sirvan para un cambio, que ha de venir desde dentro de Cuba. En cualquier caso, están escritas desde el raciocinio, la cordura, el derecho y sobre todo el sentido común.

\section{BIBLIOGRAFÍA}

Ávalos Sardiñas, H. (2008) "La inconstitucionalidad de la ley cubana de confiscaciones", Revista Otro Lunes, Revista Hispanoamericana de cultura, 2 (04).

Cantón A. (2016) Entrevista concedida por Alejandro Cantón: Presidente de Cuba Travel \& Services,

CiberCuba Noticias (2016) "Repatriación". Cibercuba.com, noticias, https://goo.gl/qMSKap (visitado 13 de abril de 2017).

Cobas Cobiella, M.E.; Pérez Gallardo, L.B.; Mendoza Díaz, J.R. (1992) "Las incapacidades para suceder en la doctrina y en el derecho positivo", Revista Cubana de Derecho, 7: 96-11.

Cobas Cobiella, M.E. (2013) "Nacionalidad y Registradores de la Propiedad. Una curiosa combinación", en Diario La Ley, XXXIV (8050): 2-15.

Cobas Cobiella, M.E. (2014) "La evolución del Derecho civil cubano y la Ley de inversión extranjera en cuba. Un camino por recorrer". Cuba in Transition, ASCE, pp. 425- 438.

Cobas Cobiella, M.E. (2015) Derecho inmobiliario en Cuba. Actualidad legislativa. Revista de Derecho Patrimonial, 37: 183-200.

Cobas Cobiella, M.E. (2016) "La empresa familiar en España y el trabajador por cuenta propia en Cuba. Aproximación a su estudio", Cuestiones Jurídicas de la Empresa familiar en España y Cuba, Cizur Menor: Thomson Reuters Aranzadi. pp. 27-66.

Cobas Cobiella, M.E. (2016) "Guía de legislación cubana", en Cuestiones Jurídicas de la Empresa familiar en España y Cuba, pp. 405-415. 
De Urrutia Barroso. L (1997) Aproximación a un análisis del proceso migratorio cubano. Papers 52, pp. 49-56, https://goo.gl/ippAQi (visitado 13 abril 2017).

Diversent, L. (2010) "El Permiso de salida en la legislación cubana", en Ajudicuba, en https://goo.gl/rmdYm6.

Diversent L. (2014) “Cambios en la política migratoria del gobierno cubano. ¿Nuevas reformas?”, Cubalex, en https://goo.gl/4x9qjE (visitado 13 abril 2017).

\section{Breve currículo:}

\section{María Elena Cobas Cobiella}

Doctora en Derecho Civil por la Universidad de Valencia. España (2001). Profesora Contratado Doctor de la Universidad de Valencia, España, acreditada a Profesor Titular de Universidad. Licenciada en Derecho por la Universidad de la Habana en 1983. Profesora de la Facultad de Derecho, Departamento Civil, Universidad de la Habana, Cuba (1983-1999). Catedrática de Derecho Civil, Facultad de Derecho, Universidad de la Habana, Cuba (1996). Notario Público en Cuba (19921998). Catedrática de la Escuela de Salud Pública del Ministerio de Salud Pública de Cuba en el área de Máster y Postgrados (1999-2000). Coordinadora de Derecho en la Universidad Europea de Madrid, 1996- 1999. Directora de varios Diplomados a nivel nacional e internacional. Directora de diversos cursos y autora de diversas obras donde destaca recientemente la Co-dirección del Tratado de Derecho de Sucesiones, 2017, Tirant Lo Blanch y del curso de especialización de Derecho de Sucesiones, Tirant Lo Blanch. 2017-2018. 